Received: 31 May 2018

Accepted: 19 November 2018

Published online: 23 January 2019
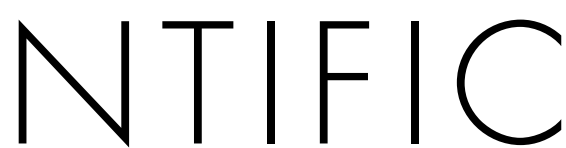

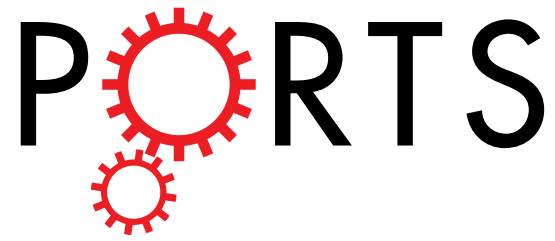

\title{
OPEN An In-Vitro Study for Early Detection and to Distinguish Breast and Lung Malignancies Using the Pcb Technology Based Nanodosimeter
}

\section{P. Venkatraman \& C. S. Sureka}

Since the early detection of cancer increases the chance of successful treatment, the present study focused to confirm the suitability of an indigenously fabricated multilayer PCB technology based 3D positive ion detector to detect breast and lung malignancy at an early stage. The 3D positive ion detector is a type of gas filled radiation detector works under the principle of ion induced ionization using an exempted micro curie activity source. Earlier studies report that malignant cells can be detected by analyzing the Volatile Organic Compounds (VOCs) exhaled by those cells that serve as eminent biomarkers for malignant detection. Based on this, the present study analyzed the signals produced in the detector by VOCs exhaled from 140 biopsy tissue samples that include tissue of normal and all stages of breast and lung malignancy. To strengthen the present data, the normal and advanced breast and lung malignant tissues were also analyzed using the Gas Chromatography- Mass Spectrometry (GC-MS). From this study, it is confirmed that the present 3D positive ion detector can be used to detect both breast and lung malignancy and also to distinguish them based on the variation in four basic physical parameters of the output pulse such as frequency, amplitude, rise time and fall time and four derived parameters of the pulse such as FWHM, area of the pulse, ionization cluster size, and ion drift time.

According to the World Health Organization (WHO) cancer fact 2017, cancer is the second leading cause of death (Cardio-vascular disease is the first cause of death in most of the population) and it causes nearly 1 in 6 deaths globally. Approximately, $70 \%$ of cancer deaths are recorded in low and middle economic countries. This is generally due to the growth, and age of the population, lifestyle includes smoking, and drinking alcohol, poor diet, physical inactivity, lack of immunity, infections etc.,

The International Agency for Research on Cancer (IARC) estimated 14.1 million new cancer cases and 8.2 million cancer deaths worldwide in 2012. The WHO estimated 8.8 million cancer deaths in 2015 which included cancer of lung, liver, colorectal, stomach, and breast in the order of $1.690,0.788,0.774,0.754$, and 0.571 million respectively. However, the IARC expected the global cancer burden of up to 21.7 million new cancer cases and 13 million cancer deaths by $2030^{1}$. Breast cancer in females and lung cancer in males are the most frequently diagnosed cancers and the leading cause of cancer death for each sex in both economically developed and developing countries, except lung cancer is preceded by prostate cancer as the most frequent cancer among males in economically developed countries. Breast malignancy is the second leading cause of deaths in women ${ }^{2}$. It is estimated that the chances of 5 years survival rate of breast malignant patients were $96 \%$ in localized condition and $86 \%$ in metastases stage in $2017^{3}$, which increased to $98.3 \%$ in localized condition ${ }^{4}$. Hence, early detection of breast malignancy is the urgent need of today to decline the rate of mortality ${ }^{5}$. However, lung malignancy is the fifth leading cause of deaths both in men and women ${ }^{6}$. In 2012, a total of 1.8 million new lung cases were estimated that accounts for $12.9 \%$ of all new cancer diagnoses. According to the Global Burden of Disease study $2020^{7}$, the five-year survival rate (17.8\%) of lung cancer was much lower than that of other leading cancers. 
In general, an invasive technique such as biopsy and non-invasive techniques such as mammography, ultrasound, Magnetic Resonance Imaging (MRI), Computed Tomography (CT) scan, Positron Emission Tomography (PET) scan are the common methods used for the detection of breast and lung malignancy. In spite of effective and frontline screening tool, the sensitivity of mammography significantly decreases in the case of heterogeneously dense breast malignancy. It failed to diagnose almost half of the palpable tumours in extremely dense breasts cases.

However, many researchers manifests that Magnetic resonance and ultrasound imaging are quite good approaches to detect malignant and invasive malignancy as compared to mammography. These imaging strategies are supposed to overcome the drawbacks of mammography. However, few researchers have shown that these screening methods result in over diagnosis, leading to increased recall and negative open surgical biopsy rates ${ }^{5,6}$. The molecular screening methods in combination with these imaging techniques are helpful in alleviating this situation $^{8,9}$

In addition to these techniques, biomarker technique is an innovative approach emerging in the last decade, which can detect malignancy in early stage too ${ }^{6}$. This technique is also useful for monitoring the progression and regression of malignant after treatment. However, the biomarker technique of malignant detection involves the search of tissues and bio-fluids. The biomarkers may be genes, proteins, metabolites and breathing compounds which provide information's about the abnormal growth of cells present in the malignant region.

To overcome the issues arised in detecting these biomarkers various techniques such as chromatography, immunohistochemistry (IHC), enzymelinked immunosorbent assay; (ELISA), two dimensional gel electrophoresis (2DE), fluorescence in situ hybridization (FISH), polymerase chain reaction (PCR), real-time polymerase chain reaction (RT-PCR), matrix-associated laser desorption/ionization time-of-flight MS (MALDI-TOF-MS), surface-enhanced laser desorption/ionization time-of-flight MS (SELDI-TOF-MS), liquid chromatography coupled with various detectors ${ }^{10-13}$ have been employed to detect the malignant cells.

Among these techniques, gas chromatography is considered to be the most appropriate and best approach due to its ease of operation, selectiveness, and reproducibility and low limits of detection. Studies reported that the GC- MS based metabolomics can be used to identify specific volatile organic compounds (VOCs) which serve as eminent source biomarkers for malignant diagnosis ${ }^{14}$. But, the identification or structural elucidation of these VOC molecules is limited due to the lack of universal metabolite- specific libraries. These drawbacks would be rectified by the emergence of various novel technologies viz., comprehensive two-dimensional gas chromatography $(\mathrm{GC} \times \mathrm{GC})$ paired with time-of-flight mass spectrometry (TOF-MS), improvement in mass spectrometer instrumentation and in algorithms for identification, development of online opened metabolomics databases ${ }^{15}$ etc. The development of nano-liquid chromatography on micro-chips is an innovation in gas chromatography as it requires samples at nano gram level and provides detection at nano or low levels ${ }^{16-18}$. However, the GC- MS technique has various limitations such as immobile system, slow, need for pre-concentration, requirement of known compound quantification, impossible for real-time measurements, compounds should be thermally stable, not suitable for clinical use etc.

Earlier studies reported that lungs emit various VOCs include Benzene, Ethylbenzene, Cyclohexane, methanol, ethanol, dodecane and tridecane, and the breast emit alkanes, alkenes, ketones, halogenated hydrocarbons, aldehydes, alcohols, esters, unsaturated hydrocarbons, terpenes, siloxanes, and aromates ${ }^{19-32}$.

In the present work, we have put forth an attempt to confirm the suitability of an indigenously fabricated multilayer PCB (Printed Circuit Board) technology based hole type 3D positive ion detector to detect breast and lung malignancy by analysing its signal variation that occurs due to variation in the emission of VOC from malignant cells. Basically, this detector combines the working principle of thick gas electron multiplier (THGEM) ${ }^{33}$ and resistive plate counter as presented by Bashkirov et al. ${ }^{34-38}$. In continuation to their research, we improved the efficiency of the detector by updating the detector structure and the same was confirmed as a gas sensor in addition to other applications ${ }^{39}$. Based on the characteristics of the 3D positive ion detector as gas sensor, the present data were obtained by collecting the VOC emitted by both normal and malignant breast and lung tissues of all stages such as stage 0 (Cancer hasn't spread), stage 1 (corresponds to local stage), stage 2 (corresponds to either local or regional stage depending on lymph node involvement), stage $3 \mathrm{a}$ (corresponds to regional stage), stage $3 \mathrm{~b}$ (may have spread to lymph nodes near the breastbone) and stage 4 (Cancer has spread beyond the lymph nodes into other parts of the body) over a range of pressure (1 to 10 Torr). In order to confirm the differential emission of VOCs between normal and malignant tissue, the Gas Chromatography- Mass Spectrometry (GC-MS) spectrum of both normal and malignant (stage 4) breast and lung tissue has also been included.

\section{Materials and Methods}

Sample collection. $\quad 10 \mathrm{mg}$ of normal and malignant breast and lung tissue of all stages were collected from concerned adult and senior patients of both sexes who were evaluated in a biopsy centre and enrolled to use their tissue specimen for clinical research. Patients with active and/or uncontrolled fungal infections, with uncertain etiology of febrile episode, with Human Immunodeficiency Virus (HIV), active or chronic hepatitis (i.e., quantifiable HBV-DNA and/or positive HbsAg, quantifiable HCV-RNA) or known history of HCV or HBV without documented resolution, tested for hepatitis B or other infections were excluded from this study. In addition, all antibiotics taken by the patients should be completed at least a week before to collect their sample. Then, the collected biopsy samples were stored with formaldehyde solution for further analysis.

Experimental setup. The indigenously developed Printed Circuit Board (PCB) technology based 3D positive ion detector was used to perform the present study. The basic structure, working principle, characteristics, and possible applications of the detector were reported in the previous article ${ }^{39}$. To short, the experimental setup consists of: (i) a vacuum chamber where the 3D positive ion detector with cathode and anode assembly, source and PIN diode were placed as shown in Fig. 1, (ii) vacuum system to evacuate the chamber, (iii) high 


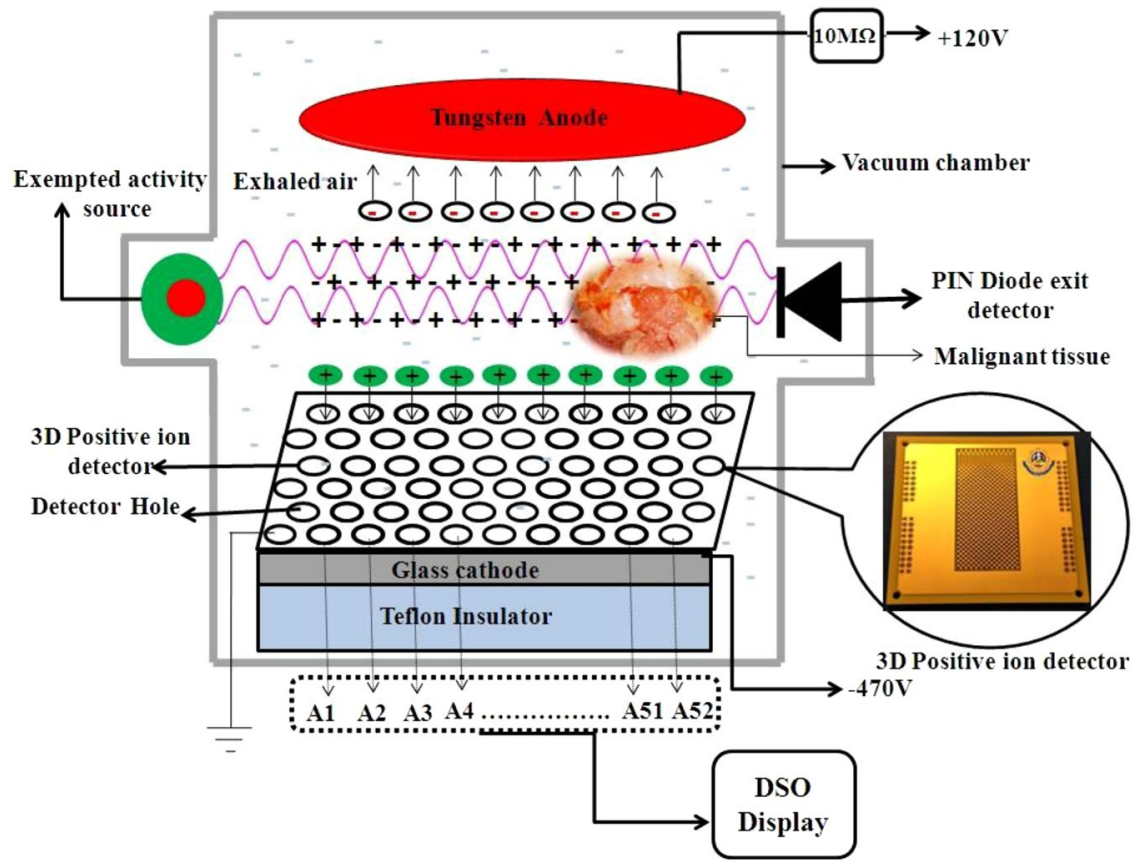

Figure 1. Schematic representation of the $3 \mathrm{D}$ positive ion detector

voltage power supply, (iv) meters to measure temperature and pressure, and (v) a four channel Digital Storage Oscilloscope (DSO) to capture the signal. One of the DSO channel was connected to the anode which collects the anode signal induced by primary electrons. The PIN diode signal was captured in another channel through a timing filter amplifier and preamplifier setup to detect the primary particles traversing the gas medium. The remaining two channels were connected to the $\mathrm{X}$ and $\mathrm{Y}$ layer of the $3 \mathrm{D}$ positive ion detector through $1 \mathrm{M} \Omega$ resistance to record the signal produced by secondary electrons.

Initially, the chamber was evacuated to remove all the molecules present inside the chamber. Then, the normal lung and breast tissues were placed independently inside the chamber. It was allowed to exhale molecules from the tissue at an appropriate pressure ranging from 1 to 10 Torr. When the ionizing photons interact with the exhaled molecules, both electrons (primary) and positive ions of those molecules are produced. The primary electrons are captured by the anode and the positive ions drift into the detector holes. The positive ions produce avalanche of electrons (secondary) inside the detector hole by "ion induced ionization". These secondary electrons are captured by the $\mathrm{X}$ and $\mathrm{Y}$ layer of the detector to produce signal in the DSO and it is recorded to analyse the amplitude, frequency, rise time, fall time and number of pulses of the signal. Then, the same experiment was performed for malignant tissues of stage $0,1,2,3 \mathrm{a}, 3 \mathrm{~b}$ and 4 independently and its DSO signal was recorded. All the measurements were repeated for 10 times for 140 tissue samples that include 10 sets of both normal and malignant breast and lung tissues at each stage.

Sample preparation for GC-MS analysis. Sample preparation protocol reported previously ${ }^{26-28}$ has been utilized in this study with minor modifications. The sample has been processed in a 96 well plate which includes the following steps. As a primary step, the stock solution for myristic-d acid has been prepared with a concentration of $1 \mathrm{mg} / \mathrm{mL}$ which was used as an internal standard (IS). Then, $10 \mathrm{mg}$ tissue of each case was mixed with $800 \mu \mathrm{L}$ methanol followed by the addition of $20 \mu \mathrm{L}$ internal standard (IS). Further this mixture has been vortexed and left on ice for 30 minutes. Then the mixture was centrifuged (Eppendorf Centrifuge $5804 \mathrm{C} / \mathrm{R}$ ) for 20 minutes at 3,500 rpm in order to remove the precipitated protein. Clear supernatant was poured into the well plate and drawn through the solid phase under vacuum condition. Before extraction, the solid phase was activated with $600 \mu \mathrm{L}$ methanol and $600 \mu \mathrm{L}$ deionized water (Milli Q). After loading the sample, the solid phase was washed with $300 \mu \mathrm{L}$ of water and eluted with $600 \mu \mathrm{L}$ methanol with eluates collected in 96 well collection plates. Finally, the eluate was evaporated under nitrogen $\left(\mathrm{N}_{2}\right)$ at room temperature. Samples were dried in Eppendorf ${ }^{\mathrm{TM}}$ Concentrator (5301) for approximately 4-5 hours (or till they were completely dry) and stored at $4^{\circ} \mathrm{C}$ till further analysis.

For Sample derivatization, $50 \mu \mathrm{L}$ methoxylamine hydrochloride in $15 \mu \mathrm{g} / \mu \mathrm{L}$ pyridine has been added and followed by mixing at $600 \mathrm{rpm}$ (Eppendorf ${ }^{\mathrm{TM}}$ Thermomixer) for nearly 2 hours at $35^{\circ} \mathrm{C}$. Further, $50 \mu \mathrm{L}$ MSTFA (with $1 \%$ trimethylchlorosilane) were added by mixing it for 60 minutes at $70^{\circ} \mathrm{C}$ with the formation of trimethylsilyl derivatives. Then the sample was centrifuged at $14,000 \mathrm{rpm}$ for 10 minutes. For GC-MS analysis, the clear supernatant was shifted quickly to inserters in the labelled GC vials by leaving the precipitate at the bottom.

Procedure for GC-MS analysis. The GC-MS analysis was carried out on 7890 A GC fitted with a GC sampler 120 (PAL LHX-AG12 - Agilent Technologies) auto sampler and coupled to Agilent 7000 Triple Quad system. A fused-silica capillary GC column, HP-5MS $30 \mathrm{~m} \times 0.25 \mathrm{~mm}$ ID, chemically bonded with a $95 \%$ dimethylpolysiloxane $5 \%$ diphenyl cross-linked stationary phase $(0.25 \mathrm{~mm}$ film thickness) was used as previously reported. 
The serum sample was inserted in the split less mode using helium as carrier gas. Initially the oven temperature was fixed at $40^{\circ} \mathrm{C}$, and then increased to $300^{\circ} \mathrm{C}$ at a rate of $10^{\circ} \mathrm{C}$ per minute. After maintaining the temperature at $300^{\circ} \mathrm{C}$ for nine minutes, it was further increased to $305^{\circ} \mathrm{C}$ for one minute. Retention time was locked to the internal standard at 15.168 minutes. Electron impact ionization (EI) was used as an ionization source for the GC-MS analysis at $70 \mathrm{eV}$. GC-MS analysis was performed according to the GC parameters also described previously. Data acquisition was done in full scan mode from $0-650 \mathrm{~m} / z$ in 0.5 seconds scan time. Hexane was run between samples to remove contamination. Mass calibration was done with perfluorotributylamine (PFTBA). A quality control (QC) sample was run after every six samples of each batch of 23 samples during GC-MS analysis.

Ethics Statement. In this study, the required biopsy tissues were collected from a nearby Biopsy Center with proper permission and informed consent from the participants. Most of the biopsy tissues ( $>98 \%)$ were used in a non-invasive manner to collect the VOCs exhaled by the tissues and returned to the same Biopsy Centre. A small portion of the remaining tissues were used to perform GC-MS analysis. All these procedures were carried out as per the Bharathiar University guidelines and regulations based on the approval of the Bharathiar University human ethical clearance committee with reference to the Ref No: BU/Med.Phys/Dr.CSS/Radiation Biology/ Human Ethical Clearance/2016 dated 12.01.2016.

\section{Results and Discussion}

Confirm suitability of the $\mathrm{PCB}$ technology based positive ion detector to detect breast malignancy. As an initial step to confirm the signal captured by the $3 \mathrm{D}$ positive ion detector, $+120 \mathrm{~V}$ was supplied to the anode through $1 \mathrm{M} \Omega$ resistance and $-470 \mathrm{~V}$ was supplied to the cathode of the detector and the DSO signal was captured in presence of the Co-60 source without placing the tissue inside the chamber. Then, the breast normal tissue followed by malignant breast tissue were placed inside the evacuated chamber to exhale the VOC molecules to the desired pressure and the DSO signals were captured. The DSO signals captured without sample, with normal and malignant breast tissue are shown in Fig. 2.

From the Fig. $2 \mathrm{a}$, it is observed that the amplitude of the signal is $3.3 \mathrm{~V}$ (addition of both $\mathrm{X}$ and $\mathrm{Y}$ layer signal) in $20 \mathrm{~ms}$ without any sample. This was taken as noise and hence all the signal parameters obtained in presence tissue were subtracted from its corresponding noise value for further analysis. From the Fig. 2b,c, it is observed that the amplitude of the detector signal with normal and malignant breast tissue is increased many fold times. This implies that the detector can be used to analyze breast malignancy of all stages.

Based on these, 10 sets of breast malignant tissue of stage $0,1,2,3 \mathrm{a}, 3 \mathrm{~b}$ and 4 were placed one by one and allowed to exhale the molecules to capture the signal. All the measurements were repeated for 10 times to improve the consistency in measurements. The mean amplitude, rise time, fall time, and frequency of pulses and number of pulses produced by normal and malignant breast tissue were compared and shown in Fig. 3(a-e). From the Fig. 3(a-e), it is observed that the signal amplitude, rise time, and fall time were constant over a range of pressure starts from 1 to 10 Torr and it increases gradually with respect to the stage of malignancy. It is also observed that there is a significant fall in frequency of pulses and number of pulses when the pressure of the gas molecules increases from 1 to 10 Torr. That is the mean frequency of the pulse emitted by normal, stage $0,1,2,3 \mathrm{a}, 3 \mathrm{~b}, 4$ breast molecules was reduced as 38.4-36.0, 83.0-74.0, 184-155, 283-261, 455-420, 497-460, and $570-530 \mathrm{~Hz}$ respectively between 1-10 Torr. Similarly, the number of pulses was reduced as 782-230, 1007-330, 1547-430, 2598- 530, 3435- 630, 3795- 730, and 6079- 830 respectively between 1-10 Torr. All these signal parameters at 1 Torr pressure were compared among normal and breast malignant tissue of all stages and given in Table 1 .

From the Table 1, it is observed that the frequency, rise time, fall time and number of pulses of the signal have been increased gradually when the normal breast tissue converted into various stages of malignancy. For the stage $0,1,2,3 \mathrm{a}, 3 \mathrm{~b}$ and 4 , the mean amplitude of the pulse produced by normal breast tissue was increased upto 2.82, $6.59,14.78,20.02,21.64$, and $22.98 \%$ respectively and the mean frequency of the signal emitted by normal breast tissue is shifted from $38.4 \mathrm{~Hz}$ to $83.2,183.5,281.2,454.5,494.5$, and $569.6 \mathrm{~Hz}$ respectively. Then, the number of pulses detected for stage $0,1,2,3 \mathrm{a}, 3 \mathrm{~b}$ and 4 of breast malignancy is $2.88,9.78,23.22,33.94,38.54$, and 67.76 times respectively higher than the pulses detected for normal breast tissue. Similarly, rise time and fall time of the stage $0,1,2,3 \mathrm{a}, 3 \mathrm{~b}$ and 4 of breast malignancy signal is $1.33,10.73 ; 1.86,25.42 ; 4.37,44.07 ; 5.15,51.97 ; 9.71,63.27$; and $15.92 \%, 77.96 \%$ respectively higher than that of normal breast tissue.

In addition, there is a significant variation in the ICSD (Ionization Cluster Size Distribution) and ion drift time of the detector among normal and breast malignant tissues. It is shown in Figs 4, 5 respectively and data are tabulated in Table 2. From the Table 2, it is noted that the number of ionization produced by the VOC molecules exhaled by stage $0,1,2,3 \mathrm{a}, 3 \mathrm{~b}$ and 4 of breast malignancy is $4.12,11.58,26.41,37.50,41.87$, and 75.37 times respectively higher than that of normal tissues. Similarly, the ion drift time in presence of stage $0,1,2,3 \mathrm{a}, 3 \mathrm{~b}$ and 4 of breast malignant tissue is also 15.92, 17.74, 20.29,27.31, and 45.19, 50.04 times respectively higher than that of normal tissues.

From the data obtained from the indigenously fabricated 3D positive ion detector, it is observed that the number, composition and type of VOC molecules exhaled by normal and malignant breast tissues may be different. To confirm this, the GCMS of normal and stage 4 malignant breast tissues were taken and shown in Figs 6,7. From these Figs 6,7, it is observed that the normal breast tissue exhaled five VOCs namely Galactose, Dimethyldodecane, Glyceryl Stearate, Tetradecane, and Methyl Stearate. However, the stage 4 breast malignant tissue exhaled twelve VOCs namely Amphetamine, Hexanal, Heptanal, Silane Tetramethyl, Phenyglyoxal, Octanal, Phenol, Decanal, Nonanal, Methanol, Ethanol, and N-Propanol. It confirmed the observation of the 3D positive ion detector. Based on these, it is confirmed that the $3 \mathrm{D}$ positive ion detector can be used to diagnose and distinguish normal and breast malignancy of all stages. 

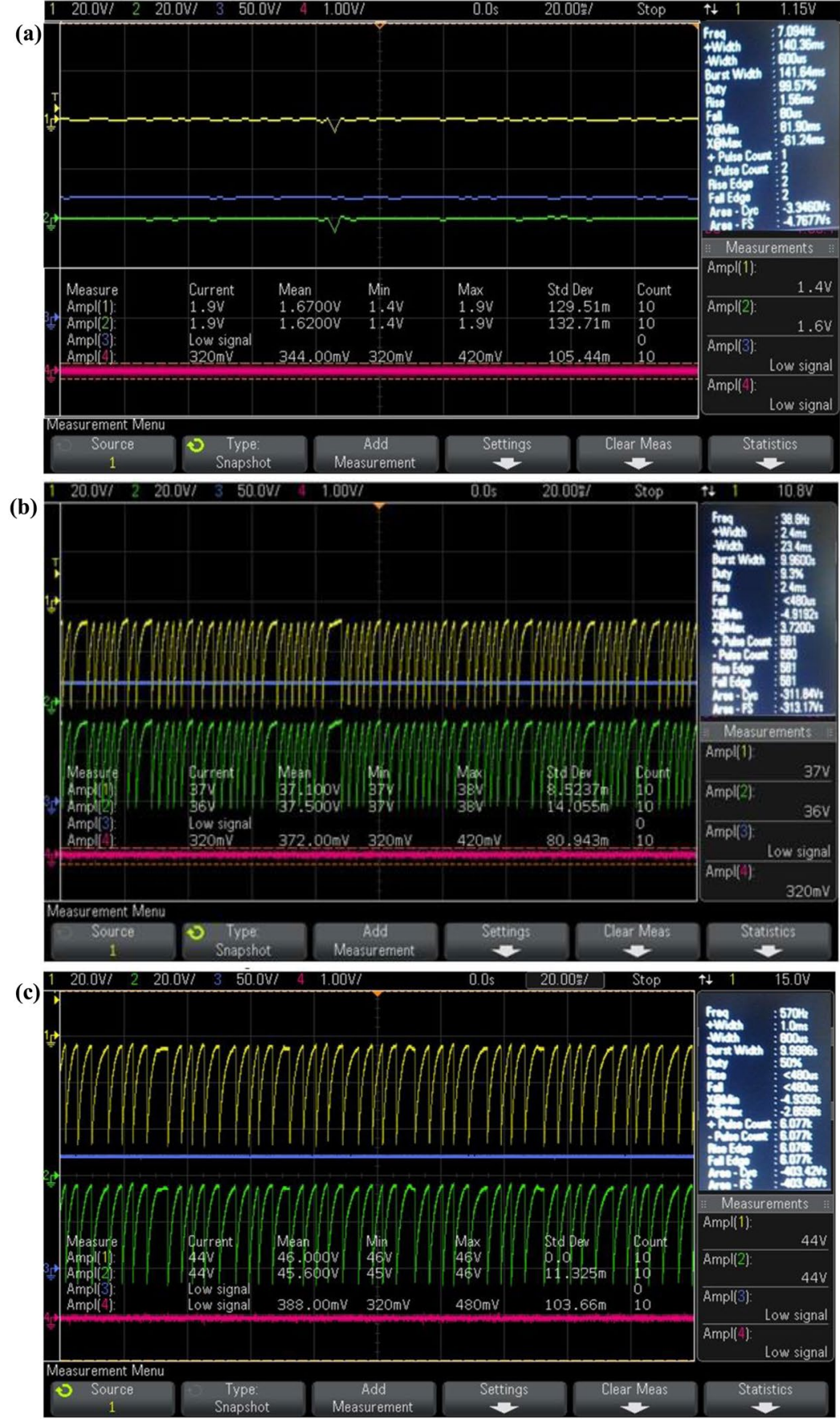

Figure 2. DSO signal captured by the $3 \mathrm{D}$ positive ion detector (a) without sample (b) in presence of normal breast tissues, and (c) Malignant breast tissue of stage 4 .

Confirm suitability of the $\mathrm{PCB}$ technology based 3D positive ion detector to detect lung malignancy. As an initial step to confirm the signal captured by the 3D positive ion detector, $+120 \mathrm{~V}$ was supplied to the anode through $1 \mathrm{M} \Omega$ resistance and $-470 \mathrm{~V}$ was supplied to the cathode of the detector and the DSO signal was captured in presence of the Co-60 source without placing the tissue inside the chamber. Then, the lung normal tissue followed by malignant lung tissue were placed inside the evacuated chamber to exhale the VOC molecules to the desired pressure and the DSO signals were captured. The DSO signals captured with normal and malignant lung tissue are shown in Fig. 8.

From the Fig. 8a,b, it is observed that the amplitude of the detector signal with normal and malignant lung tissue is increased many fold times. This implies that the detector can be used to analyze lung malignancy of all stages.

Based on these, 10 sets of lung malignant tissue of stage $0,1,2,3 \mathrm{a}, 3 \mathrm{~b}$ and 4 were placed one by one and allowed to exhale the molecules to capture the signal. All the measurements were repeated for 10 times to improve the consistency in measurements. The mean amplitude, rise time, fall time, and frequency of pulses and number 


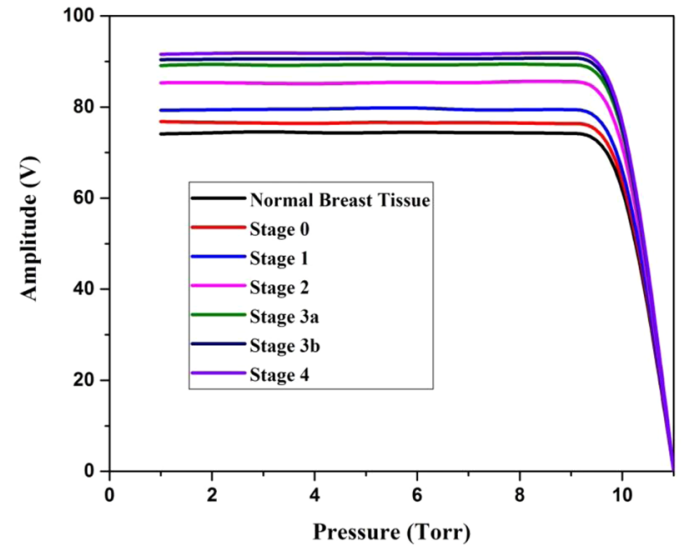

(a)

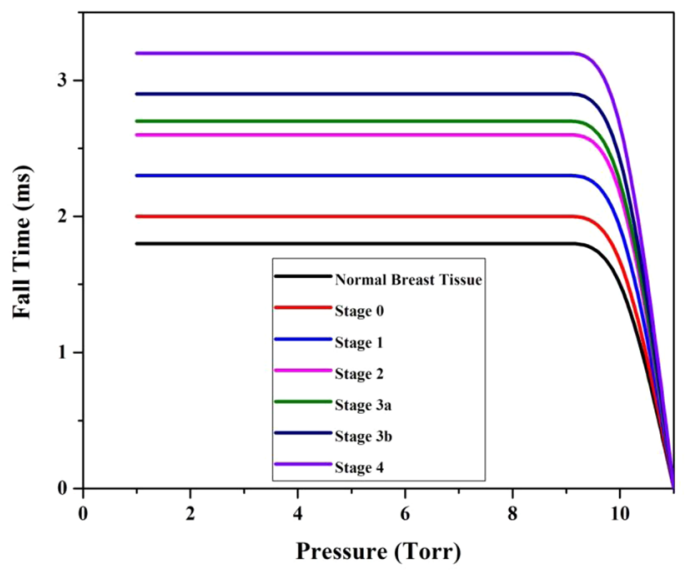

(c)

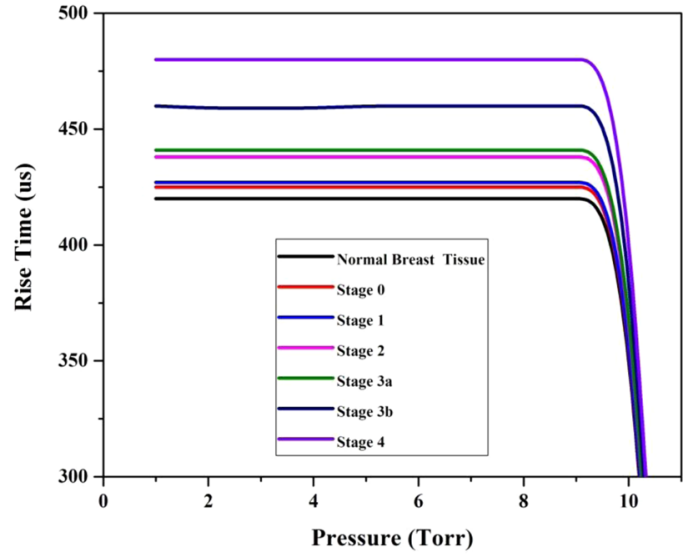

(b)

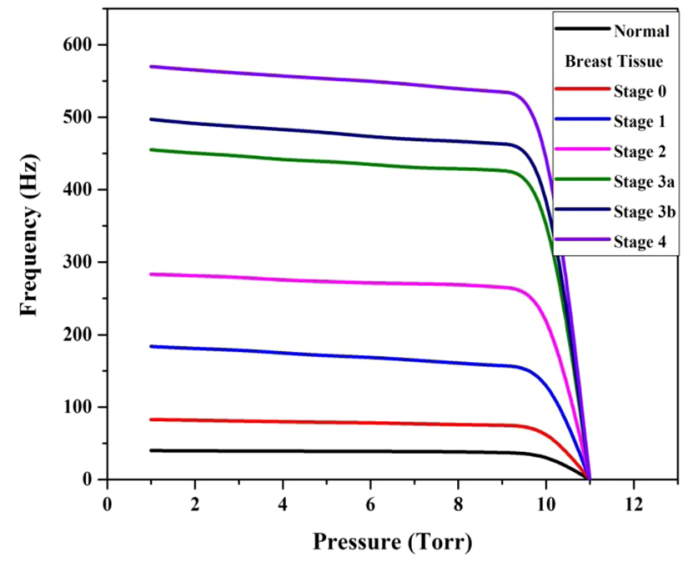

(d)

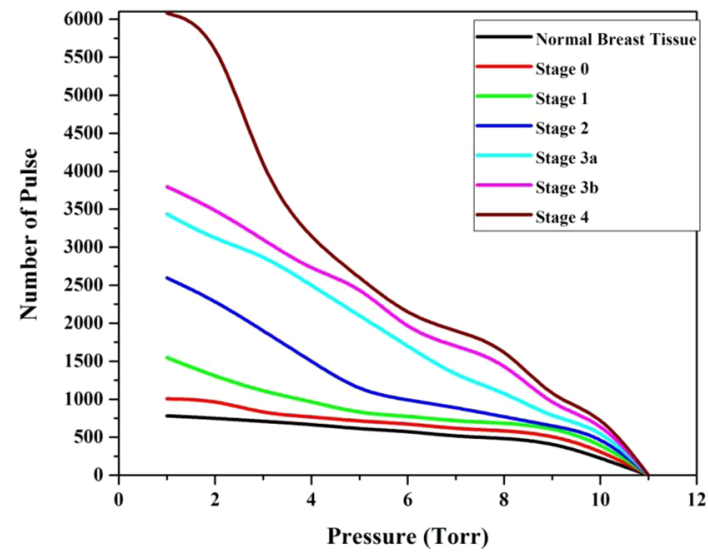

(e)

Figure 3. (a-e). Comparison of the signal amplitude, rise time, fall time, frequency, and number of pulse between normal and different breast malignant tissues medium.

of pulses produced by normal and malignant lung tissue were compared and shown in Fig. 9(a-e). From the Fig. 9(a-e), it is observed that the signal amplitude, rise time, and fall time were constant over a range of pressure starts from 1 to 10 Torr and it increases gradually with respect to the stage of malignancy. It is also observed that there is a significant fall in frequency of pulses and number of pulses when the pressure of the gas molecules increases from 1 to 10 Torr. That is the mean frequency of the pulse emitted by normal, stage $0,1,2,3 \mathrm{a}, 3 \mathrm{~b}, 4$ lung molecules was reduced as 16.6-14.9, 21.5- 18.0, 25.9- 22.0, 29.3- 26.1, 34.9- 31.9, 36.9- 35.0, and 43.9- $41.5 \mathrm{~Hz}$ respectively between 1-10 Torr. Similarly, the number of pulses was reduced as 580-90, 894- 110, 957-230, 1185350, 2393-390, 2793-400, and 3008- 500 respectively between 1-10 Torr. All these signal parameters at 1 Torr pressure were compared among normal and breast malignant tissue of all stages and given in Table 3. 


\begin{tabular}{|c|c|c|c|c|c|c|c|c|c|}
\hline \multicolumn{2}{|c|}{ Parameters/Breast } & \multirow{2}{*}{$\begin{array}{l}\begin{array}{l}\text { Without } \\
\text { Sample }\end{array} \\
3.3-3.6\end{array}$} & \multirow{2}{*}{\begin{tabular}{|l|} 
Normal \\
$74.0-74.7$
\end{tabular}} & \multirow{2}{*}{\begin{tabular}{|l|} 
Stage 0 \\
$76.1-76.8$
\end{tabular}} & \multirow{2}{*}{$\frac{\text { Stage } 1}{79.0-79.7}$} & \multirow{2}{*}{\begin{tabular}{|l} 
Stage 2 \\
$85.0-85.7$
\end{tabular}} & \multirow{2}{*}{\begin{tabular}{|l|} 
Stage 3a \\
$88.1-89.8$ \\
\end{tabular}} & \multirow{2}{*}{\begin{tabular}{|l|} 
Stage 3b \\
$90.4-90.7$
\end{tabular}} & \multirow{2}{*}{\begin{tabular}{|l} 
Stage 4 \\
$91.0-91.9$
\end{tabular}} \\
\hline \multirow{5}{*}{ Amplitude (V) } & Range & & & & & & & & \\
\hline & Mean & 3.57 & 74.4 & 76.5 & 79.3 & 85.4 & 89.3 & 90.5 & 91.5 \\
\hline & $\sigma^{2}$ & 0.0045 & 0.05 & 0.10 & 0.04 & 0.05 & 0.06 & 0.04 & 0.07 \\
\hline & 6 & 0.067 & 0.22 & 0.32 & 0.22 & 0.23 & 0.25 & 0.21 & 0.27 \\
\hline & $\%$ & - & - & 2.82 & 6.59 & 14.78 & 20.02 & 21.64 & 22.98 \\
\hline \multirow{5}{*}{ Frequency $(\mathrm{Hz})$} & Range & $7.0-7.1$ & $36-38.8$ & $83-84$ & $182-184$ & $279-282$ & $453-455$ & \begin{tabular}{|l|}
$493-495$ \\
\end{tabular} & \begin{tabular}{|l|}
$568-570$ \\
\end{tabular} \\
\hline & Mean & 7.01 & 38.4 & 83.2 & 183.5 & 281.2 & 454.5 & 494.5 & 569.6 \\
\hline & $\sigma^{2}$ & 0.001 & 0.76 & 0.17 & 0.5 & 0.06 & 0.5 & 0.72 & 0.48 \\
\hline & 6 & 0.03 & 0.87 & 0.42 & 0.707 & 0.03 & 0.707 & 0.84 & 0.7 \\
\hline & $\%$ & - & - & 116.66 & 377.86 & 632.29 & 1083.59 & 1187.76 & 1383.33 \\
\hline \multirow{5}{*}{$\begin{array}{l}\text { Number of } \\
\text { Pulse in } 1 \mathrm{~s}\end{array}$} & Range & $1-3$ & $781-782$ & $1006-1008$ & $1545-1547$ & $2596-2598$ & $3434-3435$ & $3793-3795$ & $6077-6079$ \\
\hline & Mean & 2.8 & 781.7 & 1007.5 & 1546.6 & 2597.5 & 3434.9 & 3794.6 & 6078.6 \\
\hline & $6^{2}$ & 0.36 & 0.21 & 0.45 & 0.44 & 0.65 & 0.09 & 0.44 & 0.44 \\
\hline & 6 & 0.63 & 0.483 & 0.7 & 0.67 & 0.85 & 0.32 & 0.69 & 0.69 \\
\hline & Times & - & - & 2.88 & 9.78 & 23.22 & 33.94 & 38.54 & 67.76 \\
\hline \multirow{5}{*}{ Rise Time $(\mu \mathrm{s})$} & Range & $179-180$ & $410-420$ & $423-425$ & $426-427$ & $434-438$ & $438-441$ & $458-460$ & $480-490$ \\
\hline & Mean & 179.8 & 418.9 & 424.5 & 426.7 & 437.2 & 440.5 & 459.6 & 485.6 \\
\hline & $6^{2}$ & 0.177 & 0.98 & 0.5 & 0.23 & 0.16 & 0.94 & 0.26 & 0.178 \\
\hline & 6 & 0.42 & 0.31 & 0.71 & 0.48 & 0.103 & 0.97 & 0.51 & 0.42 \\
\hline & $\%$ & - & - & 1.33 & 1.86 & 4.37 & 5.15 & 9.71 & 15.92 \\
\hline \multirow{5}{*}{ Fall Time (ms) } & Range & $0.5-1.0$ & $1.7-1.8$ & $1.9-2.0$ & $2.1-2.3$ & $2.4-2.6$ & $2.6-2.7$ & $2.8-2.9$ & $3.0-3.2$ \\
\hline & Mean & 0.86 & 1.77 & 1.96 & 2.22 & 2.55 & 2.69 & 2.89 & 3.15 \\
\hline & $6^{2}$ & 0.03 & 0.002 & 0.002 & 0.005 & 0.0045 & 0.0009 & 0.0009 & 0.0045 \\
\hline & 6 & 0.19 & 0.048 & 0.052 & 0.078 & 0.071 & 0.03 & 0.32 & 0.071 \\
\hline & $\%$ & - & - & 10.73 & 25.42 & 44.07 & 51.97 & 63.27 & 77.96 \\
\hline
\end{tabular}

Table 1. Data taken from the 3D positive ion detector to confirm the breast malignancy. NOP - Number of Pulses; $\sigma^{2}$ - Variance; 6 - Standard Deviation.

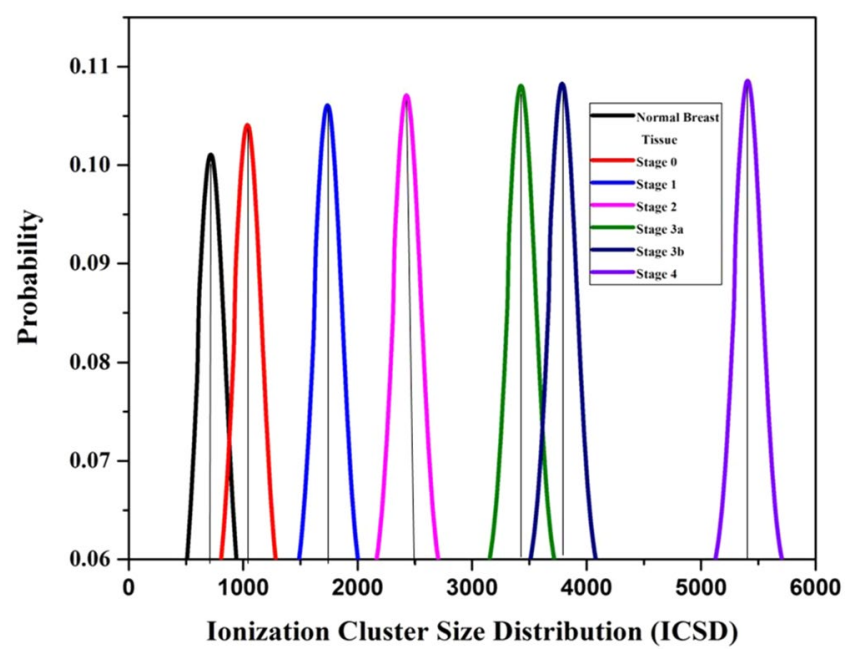

Figure 4. Ionization cluster size distribution under normal various breast malignant tissue media in presence of Co-60 source.

From the Table 3, it is observed that the frequency, rise time, fall time and number of pulses of the signal have also been increased gradually when the normal lung tissue converted into various stages of malignancy. For the stage $0,1,2,3 \mathrm{a}, 3 \mathrm{~b}$ and 4 , the mean amplitude of the pulse produced by normal breast tissue was increased upto $2.45,6.18,10.89,12.12,15.12$, and $17.84 \%$ respectively and the mean frequency of the signal emitted by normal lung tissue is shifted from $16.6 \mathrm{~Hz}$ to $21.15,24.8,28.7,33.8,35.6$, and $43.02 \mathrm{~Hz}$ respectively. Then, the number of pulses detected for stage $0,1,2,3 \mathrm{a}, 3 \mathrm{~b}$ and 4 of lung malignancy is 5.41, 6.18, 10.42,31.23, 38.12, and 41.82 times respectively higher than the pulses detected for normal lung tissue. Similarly, rise time and fall time of the stage 0 , 


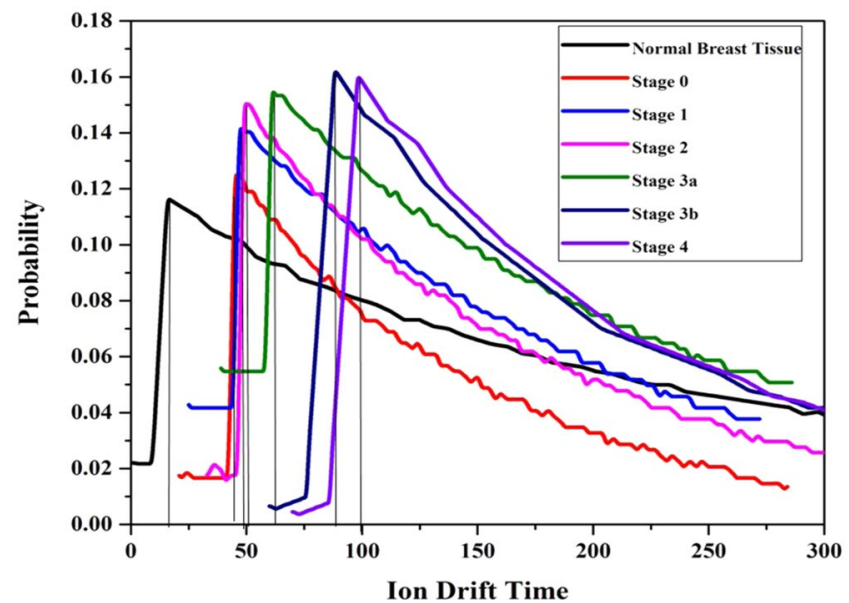

Figure 5. Ion Drift Time under normal various breast malignant tissue media in presence of Co-60 source.

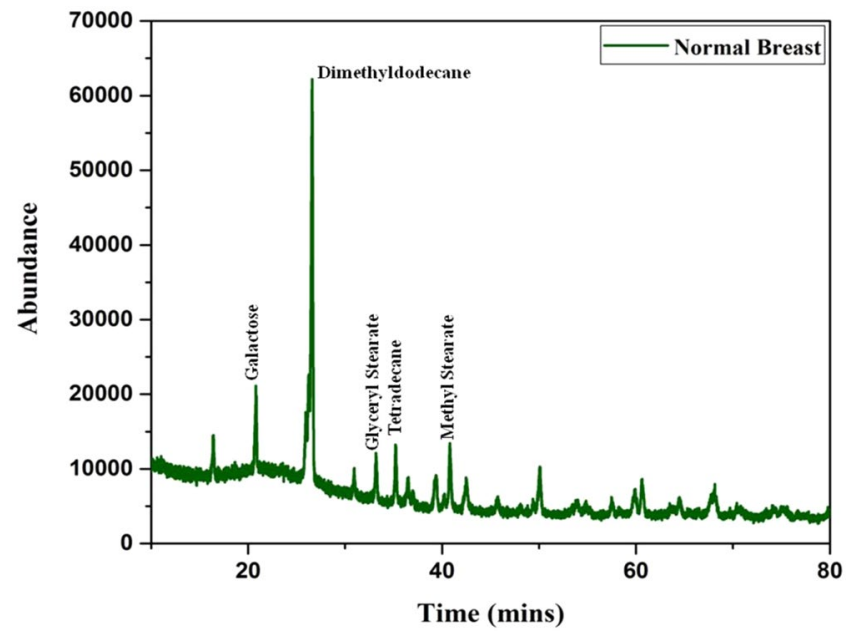

Figure 6. The typical total ion chromatograms (TICs) of breast healthy control.

\begin{tabular}{|c|c|c|c|c|c|c|c|c|c|}
\hline \multicolumn{2}{|c|}{ Parameters/Breast } & \multirow{2}{*}{$\begin{array}{l}\text { Without } \\
\text { Sample } \\
0-3\end{array}$} & \multirow{2}{*}{\begin{tabular}{|l} 
Normal \\
$713-715$ \\
\end{tabular}} & \multirow{2}{*}{$\begin{array}{l}\text { Stage 0 } \\
1008-1010\end{array}$} & \multirow{2}{*}{\begin{tabular}{|l|} 
Stage 1 \\
$1542-1543$
\end{tabular}} & \multirow{2}{*}{$\begin{array}{l}\text { Stage 2 } \\
2601-2603\end{array}$} & \multirow{2}{*}{\begin{tabular}{|l|} 
Stage 3a \\
$3339-3402$
\end{tabular}} & \multirow{2}{*}{$\begin{array}{l}\text { Stage 3b } \\
3768-3701\end{array}$} & \multirow{2}{*}{\begin{tabular}{|l|} 
Stage 4 \\
$6100-6102$
\end{tabular}} \\
\hline \multirow{5}{*}{$\begin{array}{l}\text { Ionization } \\
\text { Cluster Size } \\
\text { Distribution }\end{array}$} & Range & & & & & & & & \\
\hline & Mean & 2.6 & 714.7 & 1009.6 & 1542.8 & 2602.7 & 3395.5 & 3707.7 & 6101.8 \\
\hline & $6^{2}$ & 0.84 & 0.41 & 0.44 & 0.16 & 0.41 & 0.85 & 0.81 & 0.36 \\
\hline & 6 & 0.97 & 0.67 & 0.67 & 0.42 & 0.67 & 0.97 & 0.95 & 0.63 \\
\hline & Times & - & - & 4.12 & 11.58 & 26.41 & 37.50 & 41.87 & 75.37 \\
\hline \multirow{5}{*}{$\begin{array}{l}\text { Ion Drift } \\
\text { Time }(\mu \mathrm{s})\end{array}$} & Range & $6-7$ & $16.3-16.5$ & $41-43$ & $44-46$ & $49-50$ & $61-61.5$ & $90-91$ & 98-99 \\
\hline & Mean & 6.9 & 16.47 & 42.7 & 45.7 & 49.9 & 61.45 & 90.9 & 98.9 \\
\hline & $6^{2}$ & 0.09 & 0.0041 & 0.41 & 0.41 & 0.09 & 0.022 & 0.09 & 0.09 \\
\hline & 6 & 0.32 & 0.067 & 0.67 & 0.67 & 0.32 & 0.16 & 0.32 & 0.32 \\
\hline & \begin{tabular}{|l} 
Times \\
\end{tabular} & - & - & 15.92 & 17.74 & 20.29 & 27.31 & 45.19 & 50.04 \\
\hline
\end{tabular}

Table 2. Ionization Cluster size distribution and Ion drift time analysis to confirm the breast malignancy. ICSD- Ionization Cluster Size Distribution; IDT- Ion Drift Time; $6^{2}$ - Variance; 6 - Standard Deviation; NMR Normal to Malignancy Ratio.

$1,2,3 \mathrm{a}, 3 \mathrm{~b}$ and 4 of lung malignancy signal is $3.15,19.82 ; 7.20,36.20 ; 9.26,62.93 ; 11.90,88.79 ; 12.60,105.17 ;$ and $14.71 \%, 130.17 \%$ respectively higher than that of normal lung tissue.

In addition, there is a significant variation in the ICSD (Ionization Cluster Size Distribution) and ion drift time of the detector among normal and lung malignant tissues. It is shown in Figs 10,11 respectively and data are tabulated in Table 4. From the Table 4, it is noted that the number of ionization produced by the VOC molecules 


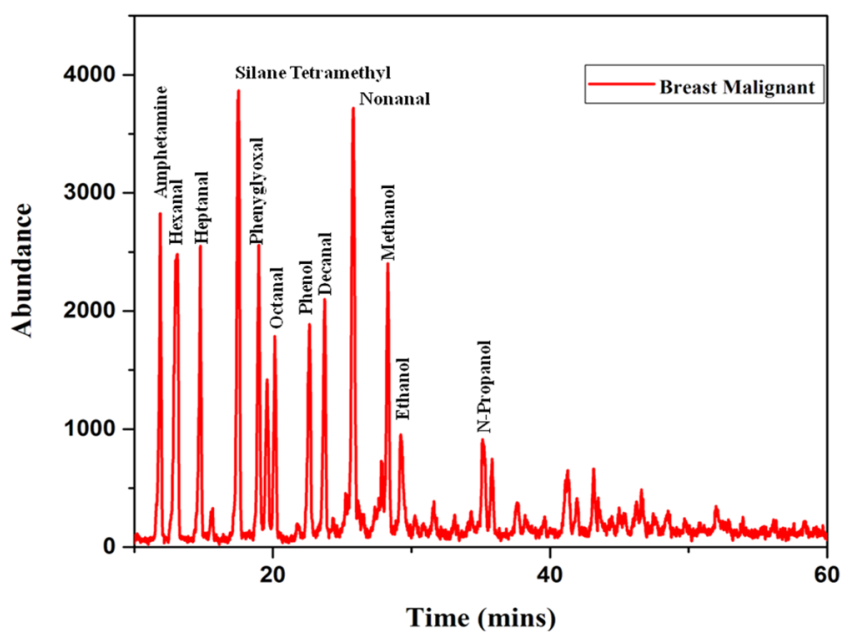

Figure 7. The typical total ion chromatograms (TICs) of breast malignant tissues.

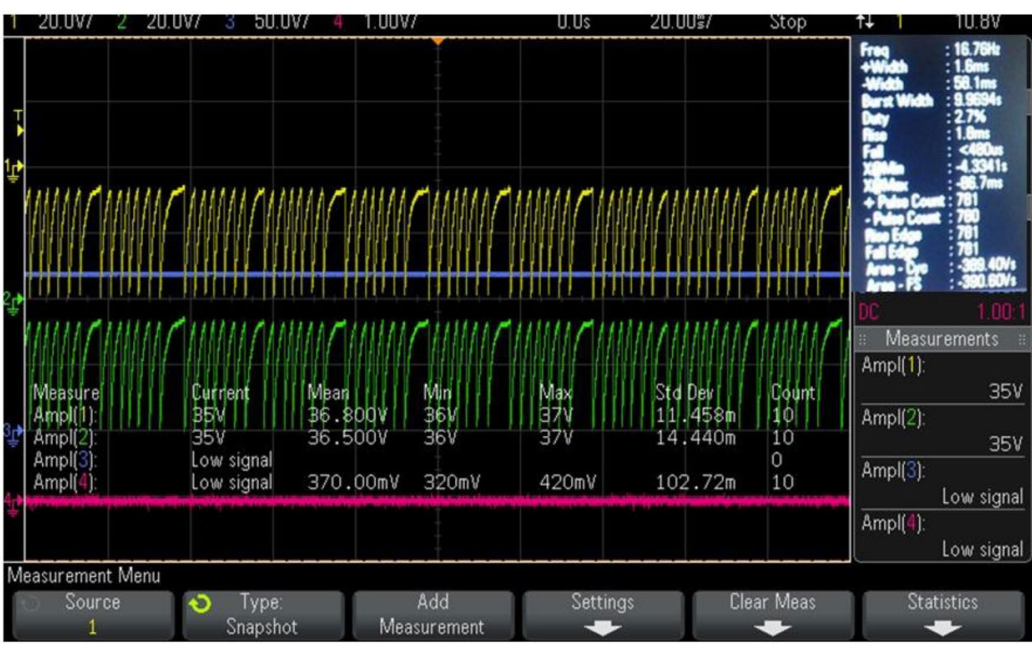

(a)

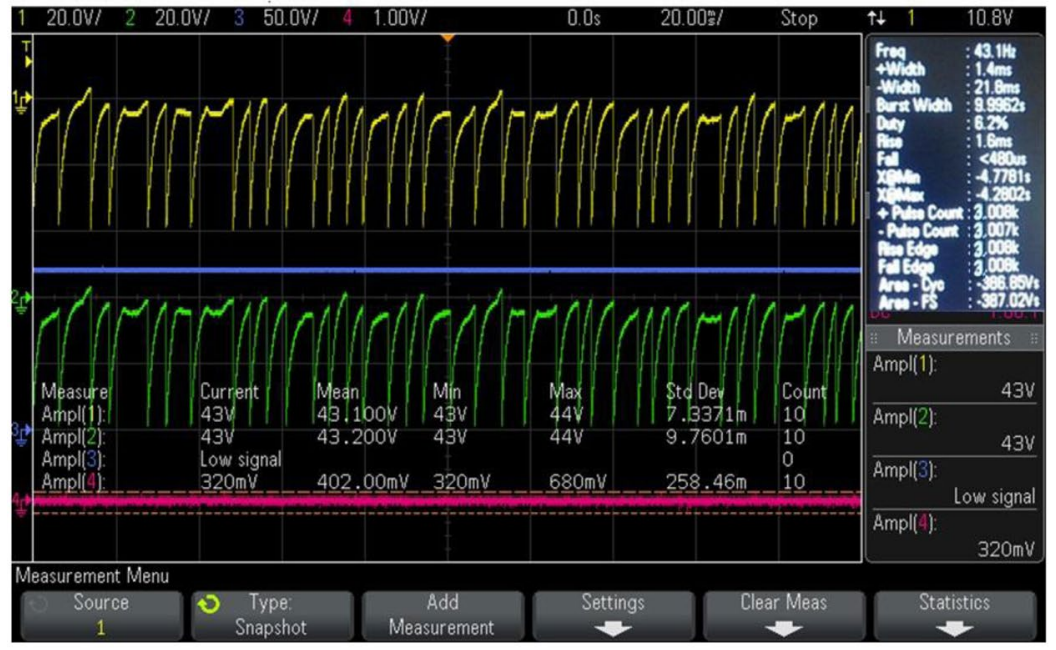

(b)

Figure 8. DSO signal captured by the 3D positive ion detector (a) in presence of normal lung tissues, and (b) Malignant lung tissue of stage 4 . 


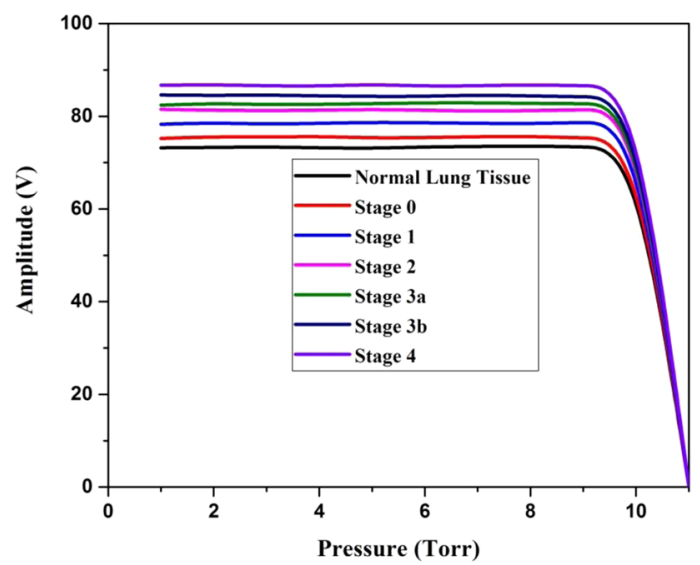

(a)

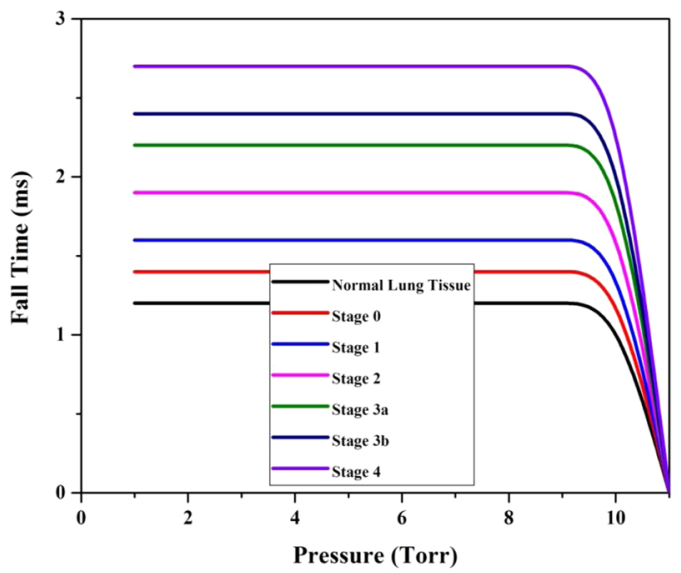

(c)

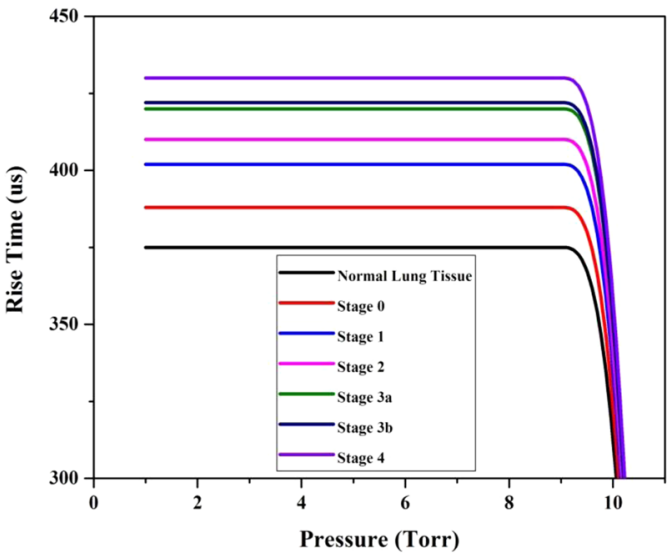

(b)

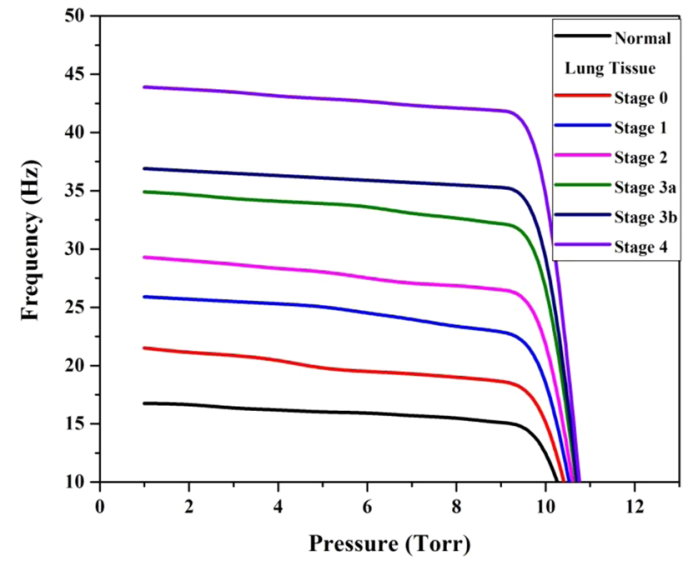

(d)

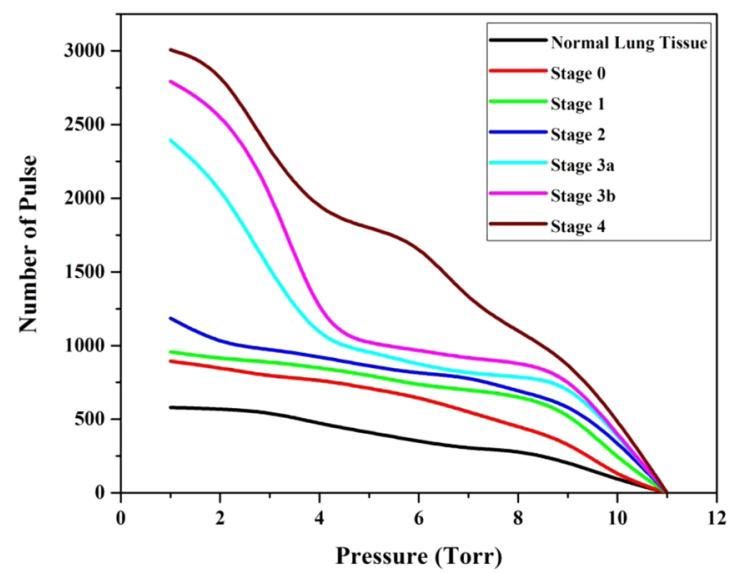

(e)

Figure 9. (a-e). Comparison of the signal amplitude, rise time, fall time, frequency, and number of pulse between normal and different lung malignant tissues medium in presence of Co-60.

exhaled by stage $0,1,2,3 \mathrm{a}, 3 \mathrm{~b}$ and 4 of lung malignancy is $6.81,8.72,10.80,33.41,40.98$, and 48.54 times respectively higher than that of normal tissues. Similarly, the ion drift time in presence of stage $0,1,2,3 \mathrm{a}, 3 \mathrm{~b}$ and 4 of lung malignant tissue is also $10.1,12.5,13.7,21.3,31.9$, and 33.9 times respectively higher than that of normal tissues.

From the data obtained from the indigenously fabricated 3D positive ion detector, it is observed that the number, composition and type of VOC molecules exhaled by normal and malignant lung tissues may be different. To confirm this, the GCMS of normal and stage 4 malignant lung tissues were taken and shown in Figs 12,13. From these Figs 12,13, it is observed that the normal lung tissue exhaled three VOCs namely Benzene, Toluene, and Butanal. However, the stage 4 lung malignant tissue exhaled eight VOCs namely Acetone, Benzene, Pentanal, Decane, Undecane, Nonanal, Ketones, and Siloxanes. It confirmed the observation of the 3D positive ion detector. 


\begin{tabular}{|c|c|c|c|c|c|c|c|c|c|}
\hline \multicolumn{2}{|c|}{ Parameters/Lung } & \multirow{2}{*}{$\begin{array}{l}\begin{array}{l}\text { Without } \\
\text { Sample }\end{array} \\
3.3-3.6\end{array}$} & \multirow{2}{*}{\begin{tabular}{|l|} 
Normal \\
$73.1-73.8$
\end{tabular}} & \multirow{2}{*}{\begin{tabular}{|l|} 
Stage 0 \\
$75.1-75.6$
\end{tabular}} & \multirow{2}{*}{\begin{tabular}{|l} 
Stage 1 \\
$78.1-78.8$
\end{tabular}} & \multirow{2}{*}{$\begin{array}{l}\text { Stage } 2 \\
81.2-81.7\end{array}$} & \multirow{2}{*}{\begin{tabular}{|l|} 
Stage 3a \\
$82.1-82.8$ \\
\end{tabular}} & \multirow{2}{*}{\begin{tabular}{|l|} 
Stage 3b \\
$84.1-84.7$
\end{tabular}} & \multirow{2}{*}{\begin{tabular}{|l} 
Stage 4 \\
$86.3-86.9$
\end{tabular}} \\
\hline \multirow{5}{*}{ Amplitude (V) } & Range & & & & & & & & \\
\hline & Mean & 3.57 & 73.4 & 75.2 & 78.4 & 81.4 & 82.3 & 84.5 & 86.5 \\
\hline & $6^{2}$ & 0.0045 & 0.051 & 0.027 & 0.047 & 0.025 & 0.05 & 0.041 & 0.065 \\
\hline & 6 & 0.067 & 0.22 & 0.16 & 0.21 & 0.15 & 0.22 & 0.20 & 0.25 \\
\hline & $\%$ & - & - & 2.45 & 6.18 & 10.89 & 12.12 & 15.12 & 17.84 \\
\hline \multirow{5}{*}{ Frequency $(\mathrm{Hz})$} & Range & $7.0-7.1$ & $16-16.76$ & $20-21.3$ & $24-25$ & $27-29$ & $33-34$ & $35-36$ & $43.0-43.1$ \\
\hline & Mean & 7.01 & 16.6 & 21.15 & 24.8 & 28.7 & 33.8 & 35.6 & 43.02 \\
\hline & $6^{2}$ & 0.001 & 0.1 & 0.16 & 0.17 & 0.45 & 0.17 & 0.20 & 0.001 \\
\hline & 6 & 0.03 & 0.3 & 0.41 & 0.42 & 0.67 & 0.42 & 0.51 & 0.04 \\
\hline & $\%$ & - & - & 27.41 & 49.39 & 72.89 & 103.61 & 114.45 & 159.16 \\
\hline \multirow{5}{*}{$\begin{array}{l}\text { Number of } \\
\text { Pulse in } 1 \mathrm{~s}\end{array}$} & Range & $1-3$ & $579-581$ & $893-895$ & 956-957 & $1185-1186$ & 2393-2394 & $2794-2793$ & 3008-3009 \\
\hline & Mean & 2.8 & 580.5 & 894.6 & 956.7 & 1185.7 & 2393.8 & 2793.6 & 3008.7 \\
\hline & $6^{2}$ & 0.36 & 0.45 & 0.48 & 0.21 & 0.21 & 0.16 & 0.24 & 0.21 \\
\hline & 6 & 0.63 & 0.71 & 0.67 & 0.48 & 0.48 & 0.42 & 0.51 & 0.48 \\
\hline & Times & - & - & 5.41 & 6.48 & 10.42 & 31.23 & 38.12 & 41.82 \\
\hline \multirow{5}{*}{ Rise Time $(\mu \mathrm{s})$} & Range & $179-180$ & $373-375$ & $382-388$ & $400-402$ & $407-410$ & $417-420$ & $421-422$ & $429-430$ \\
\hline & Mean & 179.8 & 374.5 & 386.3 & 401.5 & 409.2 & 419.1 & 421.7 & 429.6 \\
\hline & $6^{2}$ & 0.177 & 0.5 & 0.98 & 0.5 & 0.106 & 0.14 & 0.23 & 0.26 \\
\hline & 6 & 0.42 & 0.71 & 0.99 & 0.7 & 0.103 & 0.19 & 0.48 & 0.51 \\
\hline & $\%$ & - & - & 3.15 & 7.20 & 9.26 & 11.90 & 12.60 & 14.71 \\
\hline \multirow{5}{*}{ Fall Time (ms) } & Range & $0.5-1.0$ & $0.9-1.2$ & $1.3-1.4$ & $1.5-1.6$ & $1.8-1.9$ & $2.1-2.2$ & $2.3-2.4$ & $2.5-2.7$ \\
\hline & Mean & 0.86 & 1.16 & 1.39 & 1.58 & 1.89 & 2.19 & 2.38 & 2.67 \\
\hline & $6^{2}$ & 0.03 & 0.008 & 0.0009 & 0.0016 & 0.0009 & 0.0009 & 0.0016 & 0.0041 \\
\hline & б & 0.19 & 0.096 & 0.032 & 0.42 & 0.032 & 0.0 .032 & 0.042 & 0.067 \\
\hline & $\%$ & - & - & 19.82 & 36.20 & 62.93 & 88.79 & 105.17 & 130.17 \\
\hline
\end{tabular}

Table 3. Data taken from the 3D positive ion detector to confirm the lung malignancy. NOP - Number of Pulses; $\sigma^{2}$ - Variance; 6 - Standard Deviation.

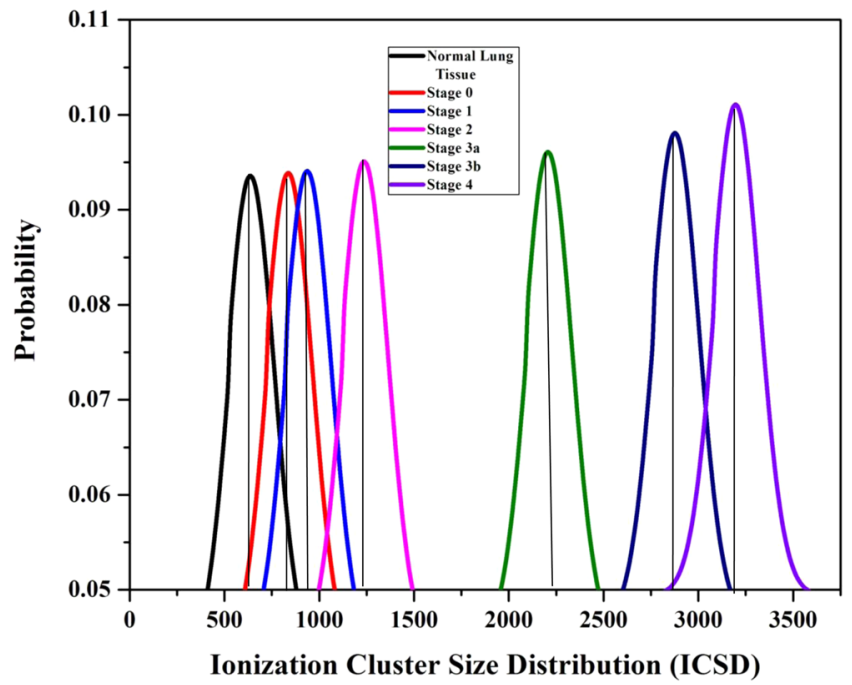

Figure 10. Ionization cluster size distribution under normal various lung malignant tissue media in presence of Co-60 source.

Based on these, it is confirmed that the 3D positive ion detector can be used to diagnose and distinguish normal and lung malignancy of all stages.

Comparison of signal between breast and lung malignancy. Followed by the confirmation of the 3D positive ion detector to diagnose breast and lung malignancies of all stages, the potential application of the detector to distinguish those malignancies was also analyzed using the same data sets. To do so, the Normal to Malignant Ratio (NMR) was calculated from the amplitude of the normal and malignant tissues. Similarly, Full 


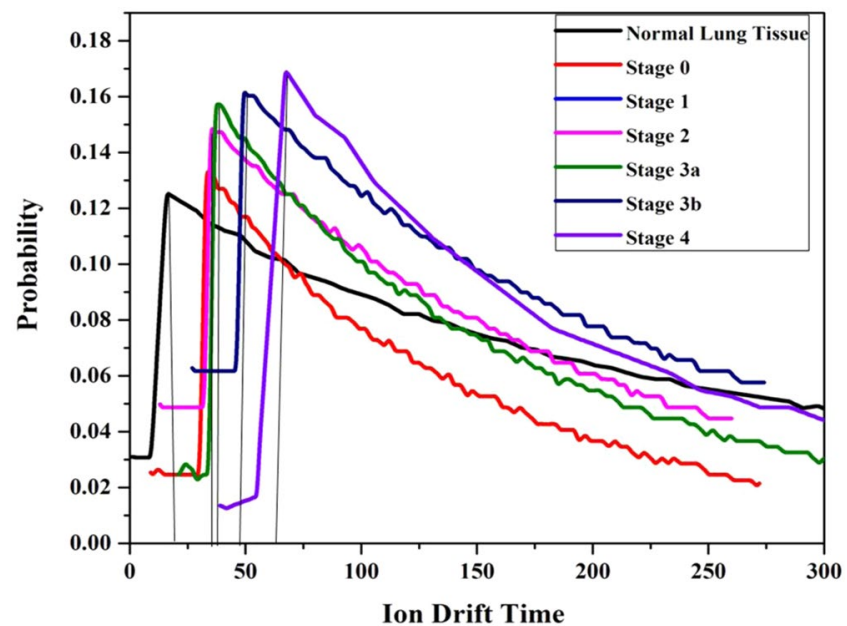

Figure 11. Ion Drift time under normal various lung malignant tissue media in presence of Co-60 source.

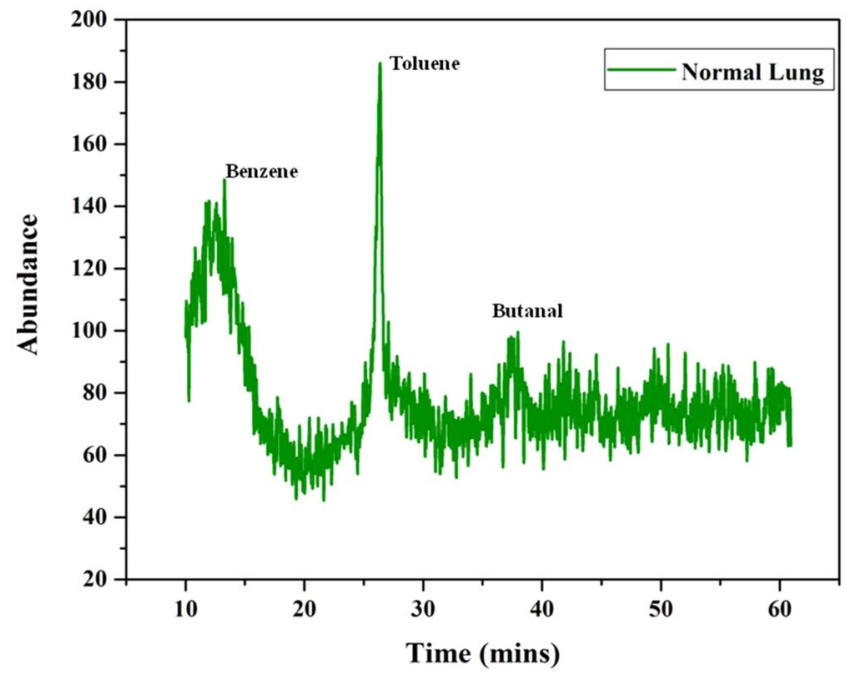

Figure 12. The typical total ion chromatograms (TICs) of lung healthy control.

\begin{tabular}{|c|c|c|c|c|c|c|c|c|c|}
\hline \multicolumn{2}{|c|}{ Parameters/Lung } & \multirow{2}{*}{\begin{tabular}{|l|}
$\begin{array}{l}\text { Without } \\
\text { Sample }\end{array}$ \\
$0-3$
\end{tabular}} & \multirow{2}{*}{$\begin{array}{l}\text { Normal } \\
528-530\end{array}$} & \multirow{2}{*}{\begin{tabular}{|l|} 
Stage 0 \\
$890-891$
\end{tabular}} & \multirow{2}{*}{$\begin{array}{l}\text { Stage 1 } \\
990-992\end{array}$} & \multirow{2}{*}{\begin{tabular}{|l|} 
Stage 2 \\
$1100-1102$
\end{tabular}} & \multirow{2}{*}{$\frac{\text { Stage 3a }}{2299-2300}$} & \multirow{2}{*}{$\frac{\text { Stage 3b }}{2700-2701}$} & \multirow{2}{*}{\begin{tabular}{|l|} 
Stage 4 \\
$3100-3101$
\end{tabular}} \\
\hline \multirow{5}{*}{$\begin{array}{l}\text { Ionization } \\
\text { Cluster Size } \\
\text { Distribution }\end{array}$} & Range & & & & & & & & \\
\hline & Mean & 2.6 & 529.7 & 890.9 & 991.7 & 1101.8 & 2299.8 & 2700.9 & 3100.9 \\
\hline & $6^{2}$ & 0.84 & 0.41 & 0.09 & 0.41 & 0.36 & 0.16 & 0.09 & 0.09 \\
\hline & 6 & 0.97 & 0.67 & 0.32 & 0.67 & 0.63 & 0.42 & 0.32 & 0.32 \\
\hline & Times & - & - & 6.81 & 8.72 & 10.80 & 33.41 & 40.98 & 48.54 \\
\hline \multirow{5}{*}{$\begin{array}{l}\text { Ion Drift Time } \\
(\mu s)\end{array}$} & Range & $6-7$ & $15-16$ & $31.5-32$ & $35-36$ & $37-38$ & $49-50$ & $65-67$ & 69-70 \\
\hline & Mean & 6.9 & 15.9 & 31.9 & 35.9 & 37.8 & 49.9 & 66.7 & 69.9 \\
\hline & $\sigma^{2}$ & 0.09 & \begin{tabular}{|l|}
0.09 \\
\end{tabular} & 0.04 & 0.09 & 0.16 & 0.09 & 0.41 & 0.09 \\
\hline & 6 & 0.32 & 0.32 & 0.21 & 0.32 & 0.42 & 0.32 & 0.67 & 0.32 \\
\hline & Times & - & - & 10.1 & 12.5 & 13.7 & 21.3 & 31.9 & 33.9 \\
\hline
\end{tabular}

Table 4. Ionization Cluster size distribution and Ion drift time analysis to confirm the lung malignancy. ICSDIonization Cluster Size Distribution; IDT- Ion Drift Time; $6^{2}$ - Variance; 6 - Standard Deviation; NMR - Normal to Malignancy Ratio.

Width Half Maximum (FWHM) and area of the individual pulses were calculated from the amplitude, rise time and fall time of the signal. The remaining important parameters such as frequency, ICSD and IDT were taken for comparison and tabulated in Table 5 and also presented as bar chart in Fig. 14 for better understanding. 


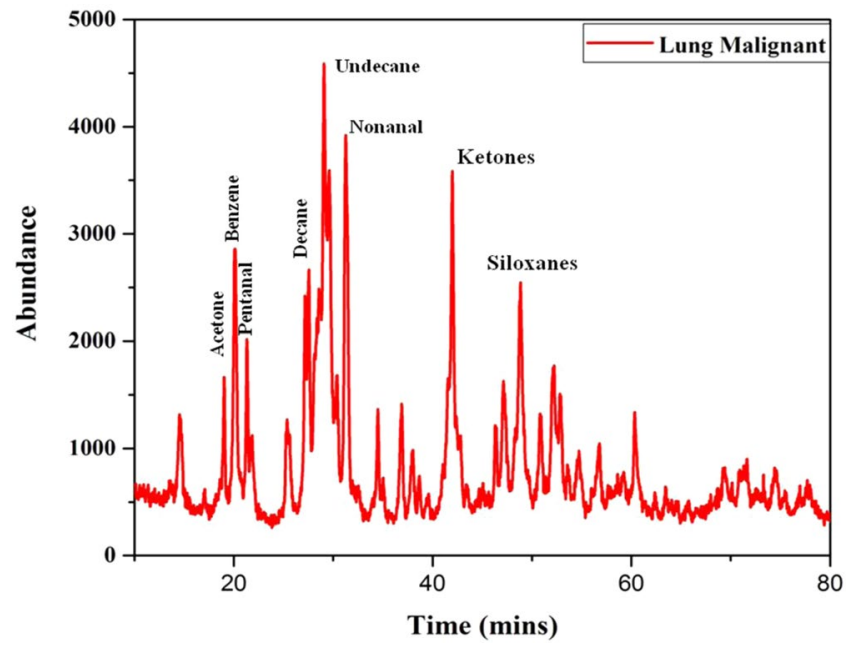

Figure 13. The typical total ion chromatograms (TICs) of lung malignant tissues.

\begin{tabular}{|c|c|c|c|c|c|c|c|c|c|}
\hline \multicolumn{2}{|l|}{ Parameter } & Normal & Stage 0 & Stagel & Stage2 & Stage3a & Stage3b & Stage4 & \\
\hline \multirow{3}{*}{\multicolumn{2}{|c|}{ NMR (\%) }} & B & 1 & 2.82 & 6.59 & 14.78 & 20.02 & 21.64 & 22.98 \\
\hline & & $\mathrm{L}$ & 1 & 2.45 & 6.18 & 10.89 & 12.12 & 15.12 & 17.84 \\
\hline & & $\%$ & 0 & 15.10 & 6.63 & 35.72 & 65.18 & 43.12 & 28.81 \\
\hline \multirow{6}{*}{$\begin{array}{l}\text { Size of the } \\
\text { pulse }\end{array}$} & \multirow{3}{*}{ FWHM (ms) } & B & 1.35 & 1.53 & 1.79 & 2.11 & 2.24 & 2.43 & 2.64 \\
\hline & & $\mathrm{L}$ & 0.78 & 1.00 & 1.18 & 1.5 & 1.8 & 1.96 & 2.24 \\
\hline & & $\%$ & 73.07 & 53.00 & 51.69 & 40.6 & 24.4 & 23.97 & 17.85 \\
\hline & \multirow{3}{*}{ Area $\left(V^{2}\right)$} & B & 2767.6 & 2926.1 & 3144.2 & 3646.3 & 3987.2 & 4095.1 & 4156.1 \\
\hline & & $\mathrm{L}$ & 2693.7 & 2827.5 & 3073.2 & 3312.9 & 3386.6 & 3570.1 & 3741.1 \\
\hline & & $\%$ & 2.74 & 3.48 & 2.31 & 9.84 & 17.73 & 14.70 & 11.09 \\
\hline \multirow{3}{*}{\multicolumn{2}{|c|}{$\begin{array}{l}\text { Ionization Cluster Size } \\
\text { Distribution }\end{array}$}} & B & 714.7 & 1009.6 & 1542.8 & 2602.7 & 3395.5 & 3707.7 & 6101.8 \\
\hline & & $\mathrm{L}$ & 529.7 & 890.9 & 991.7 & 1101.8 & 2299.8 & 2700.9 & 3100.9 \\
\hline & & $\%$ & 34.92 & 13.32 & 55.57 & 136.22 & 47.647 & 37.27 & 96.77 \\
\hline \multirow{3}{*}{\multicolumn{2}{|c|}{ Ion Drift Time $(\mu \mathrm{s})$}} & B & 16.47 & 42.7 & 45.7 & 49.9 & 61.45 & 90.9 & 98.9 \\
\hline & & $\mathrm{L}$ & 15.9 & 31.9 & 35.9 & 37.8 & 49.9 & 66.7 & 69.9 \\
\hline & & Times & 0.35 & 3.38 & 2.72 & 3.20 & 2.31 & 3.62 & 4.14 \\
\hline \multirow{3}{*}{\multicolumn{2}{|c|}{ Frequency $(\mathrm{Hz})$}} & B & 38.4 & 83.2 & 183.5 & 281.2 & 454.5 & 494.5 & 569.6 \\
\hline & & $\mathrm{L}$ & 16.6 & 21.15 & 24.8 & 28.7 & 33.8 & 35.6 & 43.02 \\
\hline & & $\%$ & 131.32 & 293.38 & 639.91 & 879.79 & 1244.67 & 1289.0 & 1224.0 \\
\hline
\end{tabular}

Table 5. Comparison of signal parameters between breast and lung malignancy.

From the Table 5 and Fig. 14, it is observed that the breast malignancy shows all the signal parameters higher than lung malignancy at all stages. This may be due to the high rate of emission of VOCs from breast than lung because of its high rate of proliferation. The NMR between the breast and lung malignancy is varied considerably at all stages. The average range of frequency of the pulse for breast and lung is $38.4-569.6$ and $16.6-43.02 \mathrm{~Hz}$ respectively that showed an independent spectrum of pulses exhaled by breast and lung malignant tissue. Hence, the frequency of pulse may be considered as one of the important parameters to distinguish breast and lung malignancy. Similarly, the average range of FWHM for breast and lung is $1.35 \mathrm{~ms}-2.64 \mathrm{~ms}$ and $0.78 \mathrm{~ms}-2.24 \mathrm{~ms}$ respectively and the average range of area under the individual pulse for breast and lung malignancy is 2767.6 $\mathrm{V}^{2}-4156.1 \mathrm{~V}^{2}$ and $2693.7 \mathrm{~V}^{2}-3741.1 \mathrm{~V}^{2}$ respectively, the average range of ICSD for breast and lung malignancy is 714.7-6101.8 and 529.7-3100.9 respectively, and the average range of IDT for breast and lung is 16.47-98.9 and 15.9-69.9 ms respectively. From this observation, it is confirmed that the $3 \mathrm{D}$ positive ion detector can be used for early detection of breast and lung malignancy and also to distinguish them.

\section{Conclusion}

We have analysed the suitability of the indigenously fabricated multilayer PCB technology based 3D positive ion detector to detect breast and lung malignancy at an early stage by collecting the VOCs exhaled by normal and malignant breast and lung biopsy tissue of all stages. To confirm the differential emission of VOCs between normal and malignant tissue, normal and advanced breast and lung malignant tissue were also analysed using the gas 


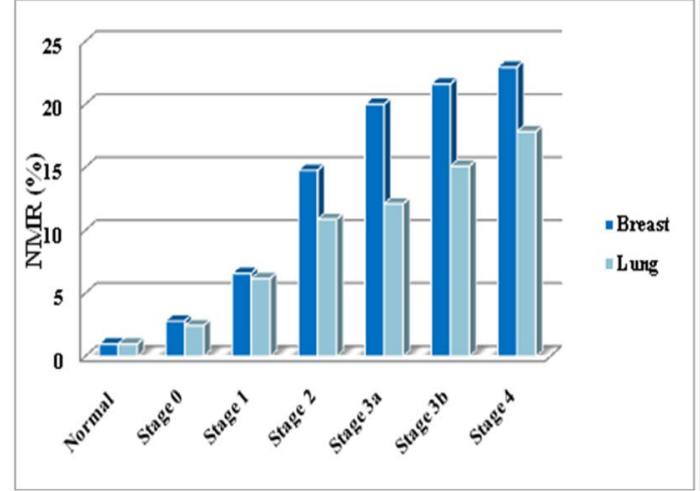

(a)

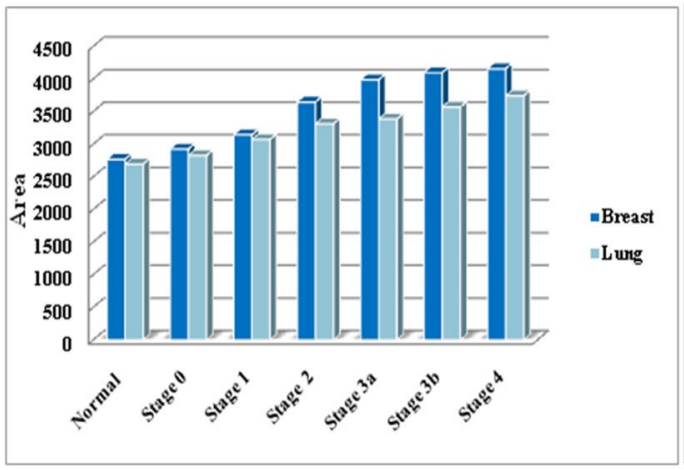

(c)

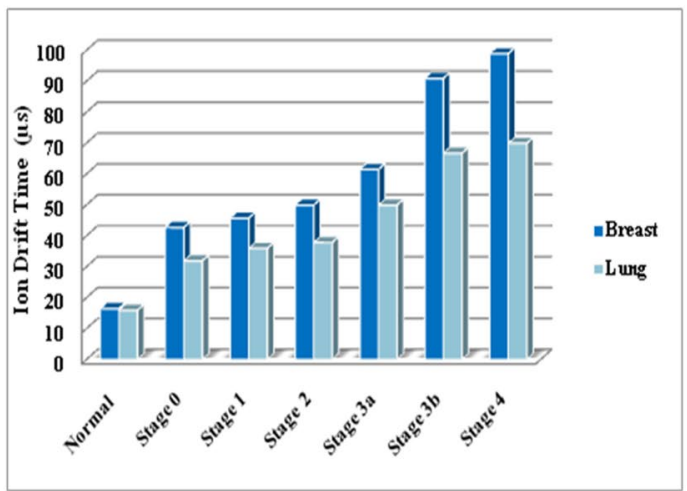

(e)

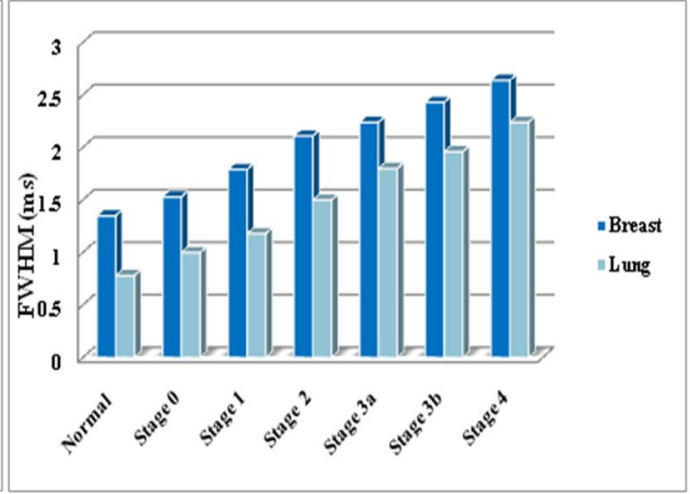

(b)

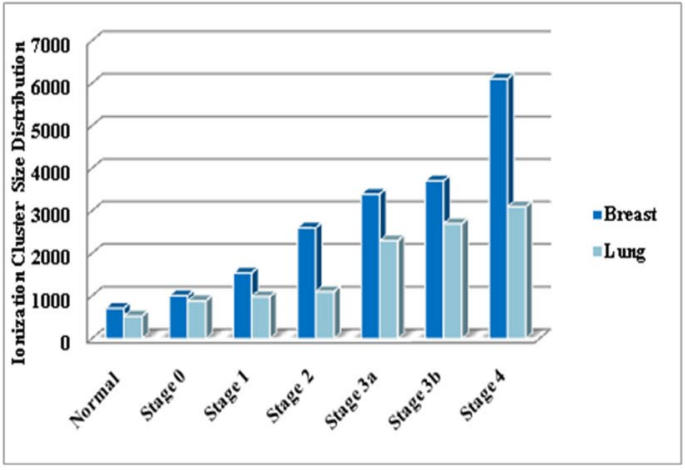

(d)

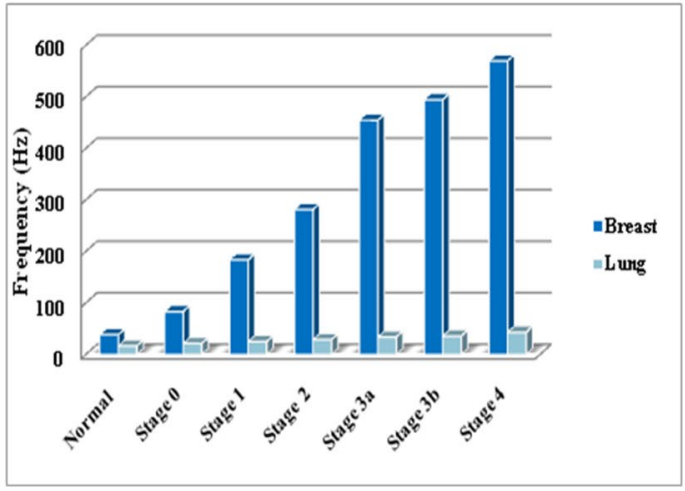

(f)

Figure 14. Comparison of signal between breast and lung malignancy through its (a) NMR, (b) FWHM, (c) Area of the pulse, (d) Ionization cluster size, (e) Ion drift time, and (f) Frequency.

chromatography-mass spectrometry (GC-MS) that is a highly accurate analytical method but it is too slow and costly to use in any routine diagnostic procedure.

Both breast and lung malignancy can be detected and distinguished at an early stage using three basic physical parameters of the pulse such as amplitude, rise time and fall time and also using derived parameters such as FWHM, area of the pulse, ionization cluster size, and ion drift time those are recorded by the detector in presence of VOCs exhaled by the samples over a range of pressure ( 1 to 10 Torr). In addition, frequency of the pulse plays a vital role as it is varied enormously among the stages of breast and lung malignancy and also between the two types of malignancy. However, it requires a constant pressure between 1 to 10 Torr. Based on these, it is confirmed that the present 3D positive ion detector can be used to detect both breast and lung malignancy and also to distinguish them. To strengthen the present results, the GCMS analysis confirmed that the VOCs exhaled by the breast and lung malignancy are different in terms of type of VOC, number of VOCs and its abundance.

The present investigation gives an opportunity to serve human society by making the present $3 \mathrm{D}$ positive ion detector as an economic, accurate, reproducible, user- friendly, portable, reliable, and non-invasive tool to detect breast and lung malignancy at an early stage by analysing the breath samples exhaled by normal and abnormal people. 


\section{References}

1. World Health Organization. Fact sheet No. 207. February 2006. Geneva, Switzerland: World Health Organization; 2006. Available at: http://www.who.int/mediacentre/factsheets/fs297/en/index.html (Accessed on: December12, 2006).

2. U.S. National Institutes of Health. National Cancer Institute. SEER Cancer Statistics Review, 1975-2011. Available at: http://www. seer.cancer.gov. Accessed on 02 December (2016).

3. James, C. R., Quinn, J. E., Mullan, P. B., Johnston, P. G. \& Harkin, D. P. BRCA1, a Potential predictive biomarker in the treatment of breast malignant. Oncologist 12, 142-50 (2007).

4. Alexander, H. et al. Proteomic analysis to identify breast malignant biomarkers in nipple aspirate fluid. Clin Malignant Res 10, 7500-10 (2004).

5. Heneghan, H. M., Miller, N., Lowery, A. J., Sweeney, K. J. \& Kerin, M. J. Micro-RNAs as novel biomarkers for breast malignant. J Oncol, Article ID 950201 (2010).

6. Siegel, R. L., Miller, K. D. \& Jemal, A., Cancer statistics, 2017 CA Cancer J Clin. 5 January (2017).

7. Vos, T. et al. Global, regional, and national incidence, prevalence, and years lived with disability for 310 diseases and injuries, 1990 2015: a systematic analysis for the Global Burden of Disease Study 2015. The Lancet 1545(388), 10053 (2016).

8. Seibert, V., Ebert, M. P. A. \& Buschmann, T. Advances in clinical malignant proteomics: SELDI-ToF-mass spectrometry and biomarker discovery. Brief Funct Genom Proteom 4, 16-26 (2005).

9. Granjolm, J. M. Facts about breast malignant. Michigan Department of Community Health, March (2010).

10. Berg, W. A. et al. Diagnostic accuracy of mammography, clinical examination, US, and MR imaging in preoperative assessment of breast malignant. Radiology 233, 830-49 (2004).

11. Smith-Bindman, R. et al. Comparison of screening mammography in the United States and the United Kingdom. JAMA 290, 2129-37 (2003)

12. Maruvada, P., Wang, W., Wagner, P. D. \& Srivastava, S. Biomarkers in molecular medicine: Malignant detection and diagnosis. Bio techniques, Suppl 9-15(2005).

13. Huang, H. L. et al. Biomarker discovery in breast malignant serum using 2-D differential gel electrophoresis /MALDI-TOF/TOF and data validation by routine clinical assays. Electrophoresis 27, 1641-50 (2006).

14. Lubes, G. \& Goodarzi, M. GC-MS based metabolomics used for the identification of cancer volatile organic compounds as biomarkers. Journal of Pharmaceutical and Biomedical Analysis 147, 313-322 (2018).

15. Lubes, G. \& Goodarzi, M. Analysis of Volatile Compounds by Advanced Analytical Techniques and Multivariate Chemometrics. Chem. Rev. 117(9), 6399-6422 (2017).

16. Ranjan, R., Esimbekova, E. N. \& Kratasyuk, V. A. Rapid biosensing tools for cancer biomarkers. Biosensors and Bioelectronics 87, 918-930 (2017)

17. Jayanthi, V. S. P. K. S. A., Das, A. B. \& Saxena, U. Urmila Saxena Recent advances in biosensor development for the detection of cancer biomarkers. Biosensors and Bioelectronics 91, 15-23 (2017).

18. Zhong, L. et al. Auto antibodies as potential biomarkers for breast malignant. Breast Malignant Res 10, R40 (2008).

19. Bouchal, P. et al. Biomarker discovery in low-grade breast malignant using isobaric stable isotope tags and two-dimensional liquid chromatography tandem mass spectrometry (iTRAQ-2DLC-MS/MS) based quantitative proteomic analysis. J Proteome Res 8 , 362-73 (2009).

20. Ali, I., Aboul-Enein, H. Y. \& Gupta, V. K. Nano Chromatography and Capillary Electrophoresis: Pharmaceutical and Environmental Analyses. Wiley \& Sons: Hoboken (2009).

21. Kobayashi, S. et al. EGFR mutation and resistance of non-small-cell lung cancer to gefitinib. N Engl J Med 352, 786-92 (2005).

22. Szulejko, J. E. et al. Evidence for cancer biomarkers in exhaled breath. IEEE Sensors Journal 10(1), 185-210 (2010).

23. di Natale, C. et al. Lung cancer identification by the analysis of breath by means of an array of non-selective gas sensors. Biosensors and Bioelectronics 18(10), 1209-1218 (2003).

24. DeSantis, C. E. et al. Breast cancer statistics, 2015: Convergence of incidence rates between black and white wome. CA Cancer J Clin 66(1), 31-42 (2016).

25. Mochalski, P. et al. Near real-time VOCs analysis using an aspiration ion mobility spectrometer. J. Breath Res. 7, 026002 (11pp) (2013).

26. Strauch, M. et al. More than apples and oranges - Detecting cancer with a fruit fly's antenna. Scientific Reports 4, 3576 (2014).

27. Li, J. et al. Worse quality of life in young and recently diagnosed breast cancer survivors compared with female survivors of other cancers: A cross-sectional study. Int. J. Cancer: 139, 2415-2425 (2016).

28. Fidler, M. M., Soerjomataram, I. \& Bray, F. A global view on cancer incidence and national levels of the human development index. Int. J. Cancer 139, 2436-2446 (2016).

29. Musharraf, S. G., Mazhar, S., Choudhary, M. I., Rizi, N. \& Atta-ur-R. Plasma metabolite profiling and chemometric analyses of lung cancer along with three controls through Gas Chromatography-Mass Spectrometry. Scientific Reports 5(8607), 1-8 (2015).

30. Musharraf, S. G., Mazhar, S., Siddiqui, A. J., Choudhary, M. I. \& Atta-ur-R. Metabolite profiling of human plasma by different extraction methods through gas chromatography-mass spectrometry - An objective comparison. Anal. Chim. Acta. 804, 180-189, https://doi.org/10.1016/j.aca.2013.10.025 (2013).

31. Palazoglu, M. \& Fiehn, O. Metabolite identification in blood plasma using GC/MS and the Agilent Fiehn GC/MS Metabolomics RTL Library. Agilent Technologies Inc. 1-8 (Accessed at www.agilent.com/chem) (2009).

32. NLSTRT (The National Lung Screening Trial Research Team), Reduced lung-cancer mortality with low-dose computed tomographic screening, The New England Journal of Medicine, vol. 365, no. 5, pp. 395-409, (2011).

33. Pszona, S., Kula, J. \& Marjanska, S. A new methods for measuring ion clusters produced by charged particles in nanometre track sections of DNA size, Nucl. Instrum. Methods Phys. Res. A, 447, 601 (2000).

34. Bashkirov, V. A \& Schulte, R. W. Ion induced impact ionization detector and uses thereof, US9213107 B2 (2009).

35. Bashkirov, V. A., Hurley, F. \& Schulte, R. W. A novel detector for 2D ion detection in low-pressure gas and its applications. IEEE Nucl. Sci. Symp. Conf. Rec. (NSS/MIC), 694 (2009).

36. Casiraghi, M., Bashkirov, V. A., Hurley, F. \& Schulte, R. W. A novel approach to study radiation track structure with nanometerequivalent resolution. Eur. Phys. J. D, 68, 111 (2014).

37. Casiraghi, M., Bashkirov, V. A., Hurley, R. F. \& Schulte, R. W. Characterization of a track structure imaging detector, Radiat. Prot. Dosim, 1-5 (2015).

38. Vasi, F., Casiraghi, M., Bashkirov, V. A., Giesen, U. \& Schulte, R. W. Development of a single ion detector for radiation track structure studies. JINST 11, C09021 (2016).

39. Venkatraman, P. \& Sureka, C. S. Fabrication and characterization of a 3D Positive ion detector and its applications. Nuclear Inst. and Methods in Physics Research, A 872, 131-138 (2017).

\section{Acknowledgements}

The authors acknowledge the Board of Research in Fusion Science and Technology (BRFST), Gujarat for financial support and the International Centre for Theoretical Physics (ICTP), Italy for knowledge up gradation. We are grateful to Dr. K. Moorthy (clinical Pathologist), India, Dr. Reinhard Schulte, USA, Dr. Vladimir Bashkirov, USA, Mr. Hurley Ford, USA, and Dr. CVS Rao, India for their valuable suggestions and timely support. 


\section{Author Contributions}

P.V. performed all the measurements and C.S.S. guided him to take measurements and written the manuscript.

Additional Information

Competing Interests: The authors declare no competing interests.

Publisher's note: Springer Nature remains neutral with regard to jurisdictional claims in published maps and institutional affiliations.

(c) Open Access This article is licensed under a Creative Commons Attribution 4.0 International License, which permits use, sharing, adaptation, distribution and reproduction in any medium or format, as long as you give appropriate credit to the original author(s) and the source, provide a link to the Creative Commons license, and indicate if changes were made. The images or other third party material in this article are included in the article's Creative Commons license, unless indicated otherwise in a credit line to the material. If material is not included in the article's Creative Commons license and your intended use is not permitted by statutory regulation or exceeds the permitted use, you will need to obtain permission directly from the copyright holder. To view a copy of this license, visit http://creativecommons.org/licenses/by/4.0/.

(c) The Author(s) 2019 